\title{
REVIEW
}

\section{Induced pluripotent stem cells in hematology: current and future applications}

\author{
D Focosi ${ }^{1,6}$, G Amabile $2,3,6$, A Di Ruscio ${ }^{2,3}$, P Quaranta ${ }^{4}$, DG Tenen ${ }^{2,5}$ and M Pistello ${ }^{4}$
}

Reprogramming somatic cells into induced pluripotent stem (iPS) cells is nowadays approaching effectiveness and clinical grade. Potential uses of this technology include predictive toxicology, drug screening, pathogenetic studies and transplantation. Here, we review the basis of current iPS cell technology and potential applications in hematology, ranging from disease modeling of congenital and acquired hemopathies to hematopoietic stem and other blood cell transplantation.

Blood Cancer Journal (2014) 4, e211; doi:10.1038/bcj.2014.30; published online 9 May 2014

\section{INDUCED PLURIPOTENT STEM CELLS}

Stem cells, generally defined as cells able to undergo self-renewal by asymmetric cell division, can be classified according to potency. Pluripotent cells, able to differentiate into any of the three germ layers, can be isolated from blastocysts (embryonic stem (ES) cells) or generated by reprogramming of adult somatic cells (induced pluripotent stem (iPS) cell) ${ }^{1}$ (Figure 1). Despite that ES cells represent the most promising type of cells for scientific and clinical applications, their use poses a set of concerns (Table 1).

The core technology of iPS cell generation consists of ectopic expression of master reprogramming factors (RFs). The iPS cells have been generated for the first time from murine fibroblasts in 2006 by Takahashi and Yamanaka ${ }^{2}$ using the transcription factors Oct4, Klf4, Sox2 and c-Myc (OKSM). In 2007, the teams of Yamanaka ${ }^{3}$ and Thomson ${ }^{4}$ successfully reprogrammed primary human fibroblasts using the OKSM cocktail ${ }^{3}$ and KIf4, Oct4, Sox2 and LIN28, ${ }^{4}$ respectively. Many groups have been able to avoid use of the proto-oncogene c-Myc because of transformation concerns $s^{5,6}$ by replacing it with less dangerous genes. ${ }^{7,8}$ In order to overcome the low transfection efficiency of primary cells, several retroviral or lentiviral vectors (LVs) have been used to introduce RFs into cells. However, the insertional mutagenesis associated with these vectors still represents a major downside of this type of approach. ${ }^{9}$ Vector integration raises additional concerns related to the stable permanence of the RFs. Prolonged and uncontrollable duration of RF expression, as well as RF silencing and spontaneous reactivation, have been shown to affect iPS cell biological properties both in vivo and in vitro. ${ }^{10,11}$ For these reasons, many efforts have been made to increase the safety of delivery approaches and to provide tightly RF controllable expression systems. To date, a wide array of delivery systems have been tested ranging from adeno-associated vectors whose parental viruses integrate in 'safe harbor' genomic sites ${ }^{12}$ to nonintegrating viral vectors (for example, Sendai virus) and to inducible vectors in which RF expression is tightly regulated by external switches. ${ }^{13}$

\section{IMMUNOGENICITY OF IPS CELL-DERIVED SOMATIC CELLS}

Although iPS cells are ideal for patient-tailored treatments for genetic disease, their derivatives could be used to treat diseases in non-histocompatible recipients. Apart from containing necrotic culture debris or induced vasculature, iPS cell products do not contain donor antigen-presenting cells, and hence in principle they would not be able to induce direct allorecognition. This property makes iPS cells immunogenic only through recipient antigen-presenting cells: a minor 'indirect pathway' leading to chronic but not acute rejections. As soon as more complex tissues will be generated, the possibility of having cells with antigen-presenting capacity would significantly increase. Until then, human leukocyte antigen (HLA) compatibility remains a suitable objective, and the creation of regional 'haplobanks' of iPS cells has been encouraged. $^{14}$

Few cell types differentiated from iPS cells appear less immunogenic than their native counterpart. For example, human iPS cell-derived hematopoietic progenitor cells induce T-cell anergy in in vitro-generated alloreactive $\mathrm{CD}^{+}{ }^{+} \mathrm{T}$ cells, and are not susceptible to natural killer (NK) cell cytotoxicity. ${ }^{15}$ This assumption cannot be considered universal, as demonstrated by the increasing immunogenicity of allogeneic cardiomyocytes derived in vivo from iPS cells. ${ }^{16}$ Furthermore, abnormal gene expression in specific differentiated cell types derived from iPS cells is able to induce T cell-dependent immune response in syngeneic recipients. ${ }^{17}$ Despite these findings, Araki et al. ${ }^{18}$ found only a limited immunogenicity of transplanted cells differentiated from iPS and ES cells. Therefore, the immunogenicity of therapeutically valuable cells derived from patient-specific iPS cells should be evaluated before any clinical application. Indeed, OCT4-specific $\mathrm{T}$ cells can be readily detected in freshly isolated $\mathrm{T}$ cells from $>80 \%$ healthy donors, $35 \%$ of patients with newly diagnosed germcell tumors and nearly $100 \%$ of these patients after chemotherapy. ${ }^{19}$

\footnotetext{
${ }^{1}$ Division of Transfusion Medicine and Transplant Biology, Azienda Ospedaliero-Universitaria Pisana, Pisa, Italy; ${ }^{2}$ Harvard Medical School, Boston, MA, USA; ${ }^{3}$ Harvard Stem Cell Institute, Boston, MA, USA; ${ }^{4}$ Retrovirus Centre and Virology Section, Department of Translational Research, University of Pisa, Pisa, Italy and ${ }^{5}$ Cancer Science Institute, National University of Singapore, Singapore, Singapore. Correspondence: Dr D Focosi, Division of Transfusion Medicine and Transplant Biology, Azienda Ospedaliero-Universitaria Pisana, via Paradisa 2, 56124 Pisa, Italy.
}

E-mail: d.focosi@ao-pisa.toscana.it

${ }^{6}$ These authors contributed equally to this work.

Received 3 March 2014; revised 26 March 2014; accepted 2 April 2014 


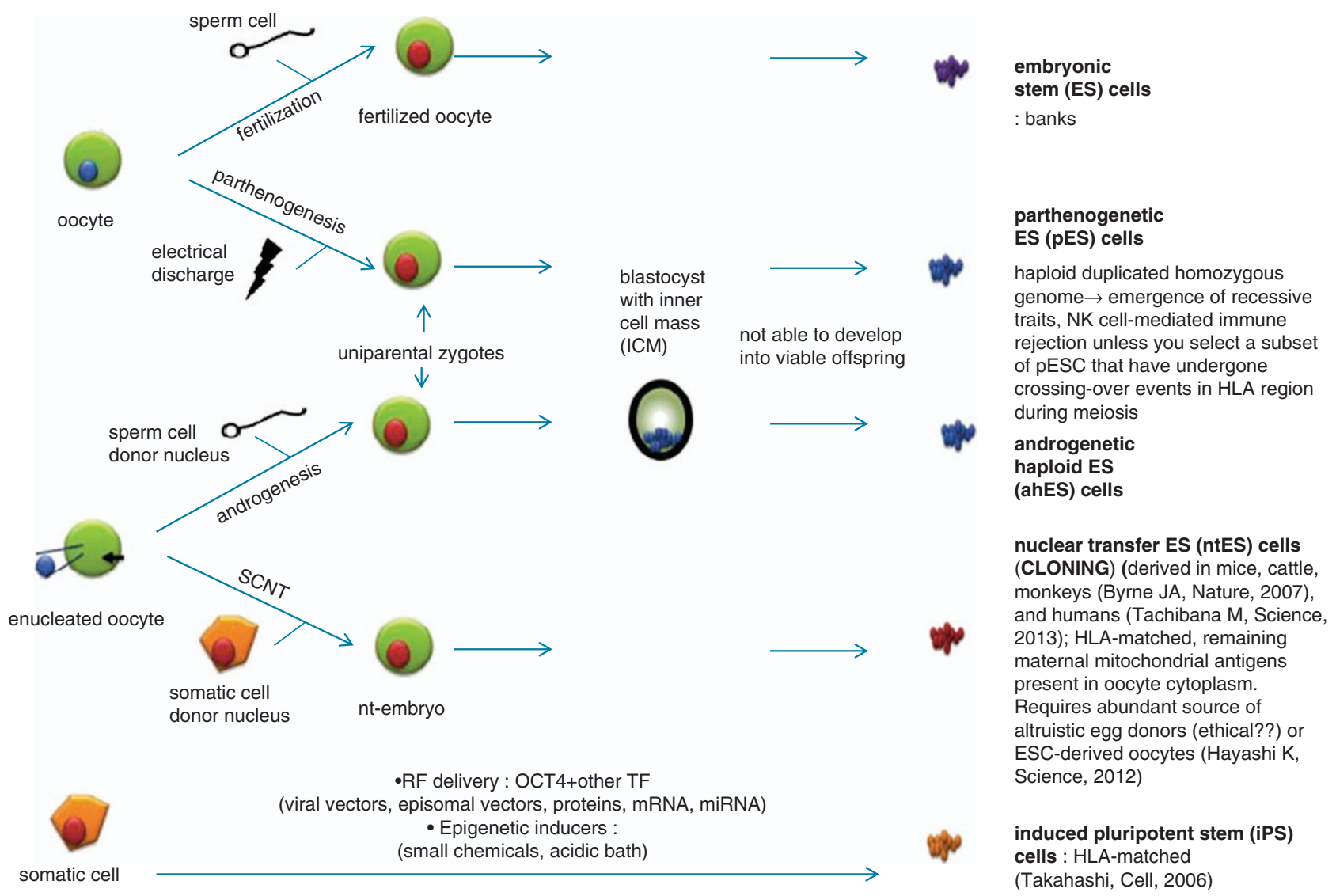

Figure 1. Different strategies to generate pluripotent stem cells.

\begin{tabular}{|c|c|c|c|c|c|c|}
\hline $\begin{array}{l}\text { ES } \\
\text { ntES } \\
\text { pES } \\
\text { ahES } \\
\text { iPS }\end{array}$ & $\begin{array}{c}++++ \\
+++ \\
++ \\
++ \\
++\end{array}$ & $\begin{array}{c}++++ \\
\text { Female only } \\
\text { Male only } \\
+\end{array}$ & $\begin{array}{c}+ \\
++ \\
+++ \\
+++ \\
++++\end{array}$ & $\begin{array}{c}+++ \\
++ \\
++ \\
++ \\
+\end{array}$ & $\begin{array}{c}+ \\
+++ \\
++ \\
++ \\
++++\end{array}$ & $\begin{array}{c}++++ \\
++ \\
+++ \\
+++ \\
+1 \\
++++\end{array}$ \\
\hline
\end{tabular}

Abbreviations: + low; ++ , moderate; +++ , high; ++++ , very high; ahES, androgenetic haploid ES cells; CNV, copy number variation; ES cell, embryonic stem cell; iPS cell, induced pluripotent stem cell; nt, nuclear transfer ES cells; pES, parthenogenetic ES cells.

\section{DISEASE MODELING}

Transgenic mice models have been generated in the attempt to recapitulate a disease phenotype; however many of these models are, in the best scenario, only similar to the human disease and often reflect incompletely the specific and relevant pathogenetic mechanisms. In particular, as iPS cells represent an early stage of disease, the establishment of in vitro differentiation models recapitulating specific cell-type differentiation would be relevant for dissecting pathogenetic events responsible for disease initiation and progression.

Understanding diseases affecting principally the bone marrow (BM) is quite limited if researchers have to only rely mostly on peripheral blood leukocytes. Specific hemopathies in which tissue samples are scarce, for example, idiopathic myelofibrosis or aplastic anemia, represent an important challenge. Patient-derived iPS cells hold promise for understanding the molecular pathways involved in disease through the establishment of 'the disease in a dish'. In particular, as iPS cells have the potential to differentiate into every cell of the hematopoietic system, cell types relevant for a specific disease can be generated recapitulating in vitro a specific-disease environment. This approach could lead to the identification of new genetic and epigenetic aberrations including environmental stress inducers that might represent a precipitating event during disease onset and otherwise not detectable.

\section{INHERITED BM FAILURE SYNDROME}

Inherited BM failure syndromes are a heterogeneous group of genetic disorders characterized by BM failure, congenital abnormalities and an increased risk of generating malignant diseases. The representative diseases with involvement of all hematopoietic lineages are the Fanconi anemia and the dyskeratosis congenita. Diamond-Blackfan anemia (DBA) is, instead, a disease affecting exclusively the erythroid lineage. To date, the only available 
therapy for these types of diseases is represented by the allogeneic hematopoietic stem cell (HSC) transplantation, even though most patients do not have fully HLA-matched donor, and those who do still have the risk of morbidity and mortality.

Low reprogramming efficiency of patient fibroblasts has been described in inherited disorders associated with activated p53, such as Diamond-Blackfan anemia, ${ }^{20}$ Fanconi anemia ${ }^{21}$ and ataxia telangiectasia. ${ }^{22}$ Transgenic expression of the implicated genes has been shown to correct the phenotype of hematopoietic cells, but in many cases gene therapy attempts have failed mainly because of the low efficiency of gene targeting and inadequate selection of real HSC population. Alternatively, gene editing of somatic cells followed by reprogramming to iPS cells and subsequent expansion and redifferentiation into HSCs can be exploited to overcome the low gene targeting efficiency. ${ }^{23}$

\section{HEMOGLOBINOPATHIES}

Hemoglobinopathies are genetic inherited conditions that originate from the lack or malfunction of the hemoglobin protein. The severe anemia combined with the complications associated with the most aggressive subtypes raises the necessity for a cure to restore the hemoglobin function. Routine therapies for these conditions, namely transfusion and iron chelation, have significantly improved the quality of life of the patients over years, despite that the pathogenetic mechanism of this group of disease remains largely unknown. A curative option is the allogeneic HSC transplantation. However, this approach is limited by both the availability of suitable donors and by the graft-versus-host disease. Gene therapy offers an alternative approach to cure hemoglobinopathies by the direct recovery of the hemoglobin function via globin gene replacement. In the past two decades, gene transfer tools based on LV development have been significantly improved and proven to be curative in several animal models for sickle cell disease (SCD) and thalassemia. ${ }^{24}$

\section{THALASSEMIAS}

The $\beta$-thalassemias are one of the most prevalent inherited disorders worldwide. They are caused by over 200 different types of either point mutations or deletions of nucleotides in $\beta$-globin gene, resulting in reduced, abnormal or no synthesis of $\beta$-globin chains. Patients affected by $\beta$-thalassemias have severe anemia and a shortened lifespan. Compound $\beta^{\mathrm{E}} / \beta^{0}$-thalassemia is the most common form of severe thalassemia in Southeast Asian countries and their diasporas. The $\beta^{\mathrm{E}}$-globin allele bears a point mutation that causes alternative splicing. The abnormally spliced form is noncoding, whereas the correctly spliced mRNA expresses a mutated $\beta^{\mathrm{E}}$-globin with partial instability. When this is compounded with a nonfunctional $\beta^{0}$ allele, a profound decrease in $\beta$-globin synthesis is observed, and approximately half of $\beta^{\mathrm{E}} / \beta^{\mathrm{O}}$-thalassemia patients are transfusion dependent. Gene therapy for $\beta$-thalassemia is particularly challenging given both the requirement for massive hemoglobin production in a lineagespecific manner and the lack of selective advantage for corrected HSCs. To date, only one adult with transfusion-dependent $\beta^{\mathrm{E}} / \beta^{\mathrm{O}}$-thalassemia major was transplanted with globin LV-transduced autologous $\mathrm{CD}_{3}{ }^{+}$cells. This patient (who is still transfusion independent at 4.5 years of follow-up ${ }^{25}$ ) showed a semidominant myeloid-biased cell clone bearing a globin lentivirus within the HMGA2 gene. The clonal dominance that accompanies therapeutic efficacy may be coincidental and stochastic or result from a hitherto benign cell expansion caused by dysregulation of the HMGA2 gene in stem/progenitor cells. ${ }^{26}$

A relevant issue to hemoglobinopathies is whether persistence of fetal hemoglobin or embryonic-fetal-adult globin class switching can occur in vivo after transplantation with human iPS cellderived HSCs. LV-transfected iPS cell-derived HSCs were compared with their LV-transfected natural isogenic somatic counterparts. In particular, NSG immunodeficient mice transplanted with the corrected cells showed an embryonic to fetal and a partial fetal to adult globin class switching. This finding suggests that the $\beta$-globin gene transfer is likely necessary for iPS cell-based therapy of the $\beta$-hemoglobinopathies. ${ }^{25}$ If HSCs will be safely derived from iPS cells, it is envisaged that patient-specific autologous iPS cells will also be routinely generated for patients affected by hemoglobinopathies and HSCs obtained by in vitro differentiation. In fact, HSCs derived from iPS cells may be corrected by gene editing (for example, transcription activator-like effector nucleases $(\text { TALENs })^{27}$ ) or modified by lentiviral transfer carrying a therapeutic gene. A screening to assess viral integration in chromosomal areas of lower genotoxic potential is likely to become an important step for this kind of approach. An alternative to $\beta$-globin gene transfer might be the erythroid-specific knockdown of BCL11A by means of small hairpin RNA, thereby forcing $\gamma$-globin expression and $\beta$-globin downregulation.

The $\alpha$-thalassemia major (hydrops fetalis) has also been corrected in transgene-free iPS cells using zinc-finger nucleasemediated insertion of a globin transgene in the AAVS1 site of human chromosome 19. Homozygous insertion of the best of the four constructs tested led to a complete correction of globin chain imbalance in erythroid cells differentiated from the corrected iPS cells. $^{28}$

\section{SICKLE CELL DISEASE}

In the majority of SCD patients, the mutation of $A>T$ (also known as $\beta^{A}$ to $\beta^{s}$ mutation) in both alleles of the $\beta$-globin $(H B B)$ gene changes codon 6 from Glu (GAG) to Val (GTG), resulting in a defective form of adult hemoglobin. An ideal iPS cell-based gene therapy for SCD would require both precise correction of diseasecausing mutation and a complete switching from fetal-type globin to adult-type globin.

Although SCD was one of the first described molecular diseases, the goal for treating this monogenic disorder using gene therapy approaches has not been fully accomplished in humans. ${ }^{29}$ Gene correction of $\beta^{s}$ in mouse ES cells by homologous recombination (HR) has previously been reported. ${ }^{30}$ Similarly, correction of the $\beta^{\text {s }}$ mutation in murine iPS cells derived from a humanized SCD mouse model, followed by successful transplantation of differentiated hematopoietic cells into isogenic mice, has been applied to cure SCD phenotypes. ${ }^{31}$ Zou et al. ${ }^{32}$ demonstrated a site-specific gene correction of the silent $H B B$ gene correction in human patient-specific iPS cells. Such corrected iPS cells could be redifferentiated in red blood cells (RBCs) expressing $25-40 \%$ of the wild-type $\beta^{\mathrm{A}}$ allele.

\section{TRANSPLANTATION OF GENETICALLY UNEDITED, IPS CELL-DERIVED HSCS}

HSCs derived from BM, umbilical cord $^{33}$ and mobilized ${ }^{34}$ or nonmobilized ${ }^{35}$ peripheral blood have been successfully used as a source for iPS cell generation. On the other hand, iPS cells obtained from different somatic cell types of humans and nonhuman primates ${ }^{36}$ can be successfully redifferentiated to HSCs (Figure 2).

To date, there are at least three efficient ways to differentiate HSCs from iPS cells. ${ }^{37}$ (1) Coculture with OP9 cells, a murine mesenchymal stem cell line established from newborn B6C3F1 osteopetrotic mouse calvaria not producing functional macrophage colony-stimulating factor. ${ }^{38}$ Coculture of OP9 cells with mouse ES cells has been used to develop a preferential differentiation induction system of pluripotent cells into hematopoietic cells other than monocytes. Although the use of mouse stroma provides a barrier to clinical translation, this barrier might be overcome if a master cell bank is produced. ${ }^{39}$ (2) Transduction of iPS cells with Lhx2, a LIM-homeobox 


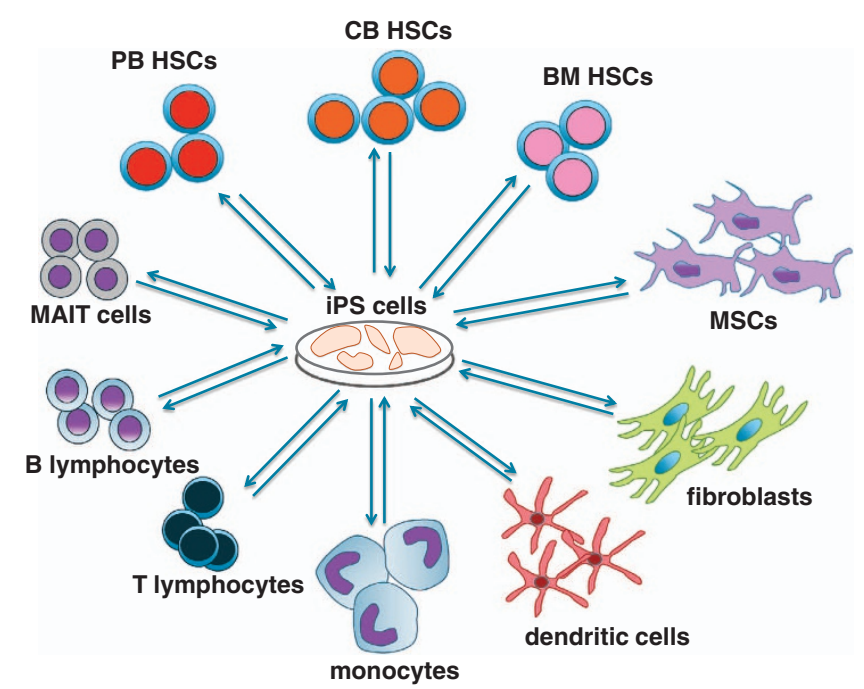

Figure 2. Summary of blood cell types successfully used as a source for iPS cell generation, and of blood cells successfully redifferentiated to blood cells to date (see text for references).

transcription factor. $^{40}$ (3) Dissociation of teratoma-generated immunodeficient mice. Our group recently showed that human iPS cells differentiate within teratomas generating functional myeloid and lymphoid cells. Similarly, HSCs can be isolated from teratoma parenchyma and reconstitute a human immune system when transplanted into NOD.Cg-Prkdc(scid) $\| 2 \mathrm{rg}(\mathrm{tm} 1 \mathrm{Wjl}) / \mathrm{Sz}$ immunocompromised (NSG) mice. ${ }^{41}$ Suzuki et al. ${ }^{42}$ reported that human iPS cell-derived HSCs migrate from teratomas into the murine BM and their intravenous injection into irradiated recipients resulted in multilineage and long-term reconstitution of the hematolymphopoietic system in serial transfers. Using this in vivo generation system, X-linked severe combined immunodeficiency mice can be treated by HSCs derived from gene-corrected clonal iPS cells. It should also be noted that neither leukemia nor tumors were observed in recipients after transplantation of iPS cell-derived HSCs. ${ }^{42}$

Other strategies have been successfully implemented with ES cells, and could theoretically be adapted to iPS cells. (1) Dissociation of human embryoid body (EB) at days $7-10 i^{43}$ however, human ES cell-derived HSCs had limited proliferative and migratory capacity compared with somatic HSCs. ${ }^{44}$ The traditional 'feeder-free' system of EB-mediated differentiation of human ES cells/iPS cells may be utilized, although it tends to be more variable in differentiation into hematopoietic progenitor cells. Alternative methods such as 'spin-EBs' aggregate undifferentiated human ES cells through centrifugation ${ }^{45}$ in the absence of murine stroma. ${ }^{46}$ (2) Coculture with monolayers of cells derived from mouse aorta-gonads-mesonephros and fetal liver, or with stromal cell lines derived from these tissues. ${ }^{47}$ (3) Ectopic expression of CDX4 and HOXB4 expression. ${ }^{48}$ (4) Culture with MEDII (medium conditioned by HepG2 cells, a human hepatocarcinoma cell line). ${ }^{49}$

Modern HSC mobilization drugs (granulocyte colony-stimulating factor and CXCR4 antagonists) make access to this type of cells particularly easy. From this point of view, transiting through the pluripotent status in order to achieve HSCs seems to be a complication. However, differentiation of HSCs from iPS cells can be particularly useful in the presence of congenital or acquired settings where HSC harvest is poor (for example, idiopathic myelofibrosis or aplastic anemia) or whenever expansion to large numbers is required. As previously stated, apart from reconstituting hematopoiesis, human iPS cell-derived HSCs also retain the unique and interesting ability to induce T-cell anergy in in vitrogenerated alloreactive $\mathrm{CD}^{+} \mathrm{T}$ cells. ${ }^{15}$

\section{TRANSPLANTATION OF IPS CELL-DERIVED, GENETICALLY} ENGINEERED AUTOLOGOUS HSCS IN GENETIC HEMOPATHIES

Genetic engineering in inherited hemopathies can be performed directly on autologous HSCs provided that they are available and prone to transfection and transduction. As both conditions are difficult to achieve, ${ }^{50}$ iPS cell technology may result in a valuable alternative. $^{51}$

Gene manipulation has been performed on iPS cells with several technologies: (1) suppression of expression, either transient or sustained, ${ }^{52}$ of disease-related genes in patientspecific iPS cells by RNA interference; (2) gene knockout; ${ }^{53}$ (3) HR that can be used for phenotypic correction of loss-of-function mutations, ${ }^{54}$ and correction or replacement of underlying diseasecausing mutations at the endogenous loci. Differently to conventional gene therapy approaches, HR ensures that the corrected gene will be expressed in an appropriate temporal and tissue-specific manner under the regulation of endogenous ciselements. HR can be pursued with several and constantly improving methods such as: (1) zinc-finger nucleases; ${ }^{55}$ (2) TALENs; TALENs efficiently recognize and cleave any given DNA sequences and, compared with zinc-finger nucleases, exhibit lower unspecific cleavage, with a reduced nuclease-associated cytotoxicity; ${ }^{56}$ (3) clustered regularly interspaced short palindromic repeats (CRISPR)/CRISPR-associated (Cas) systems in bacteria and archea use short RNA to direct degradation of foreign nucleic: this activity has been exploited for gene targeting in iPS cells, ${ }^{57,58}$ even at multiple loci simultaneously ${ }_{i}^{59}$ and (4) helper-dependent adenoviral vectors. ${ }^{60}$

Following HSC expansion at a suitable dose and, if applicable, ex vivo or in vivo selection for corrected/modified cells, appropriate pretransplantation conditioning (myeloablation) of the patient can eventually be applied before intravenous or intrabone infusion of HSCs.

\section{TRANSPLANTATION OF DIFFERENTIATED BLOOD CELL TYPES}

\section{Anucleated cells}

Because of short half-life and absence of nucleus, such cells spare investigators and patients from risks of oncogenicity, and are hence the most immediate candidates for clinical trials. This category includes most likely mature RBCs and platelets. An efficient screening to separate accurately all the anucleated cells from the nucleated counterpart appears to be a limiting step for this kind of application.

RBCs are unique, highly specialized and the most abundant cells in humans. The primary function of RBCs is transportation of the respiratory gases $\mathrm{O}_{2}$ and $\mathrm{CO}_{2}$. Meanwhile, $\mathrm{RBCs}$ are also the main antioxidant reservoir for the whole body. Blood transfusion is a common procedure in modern medicine, and it is practiced throughout the world; however, many countries report a less than sufficient blood supply. Even in developed countries where the supply is currently adequate, projected demographics predict insufficiency in this supply as early as 2050 . Once alloimmunization occurs, such patients require RBCs from donors with a different blood group antigen combination, making it a challenge to find donors after every successive episode of alloimmunization. Alternative blood substitutes such as synthetic oxygen carriers have so far proven unsuccessful. ${ }^{61}$ Transfusing iPS cell-derived RBCs (safer than transplanting genetically engineered iPS cellderived HSC) suffers from two major limitations: short half-life and need for repeated, life-long transfusions. Nevertheless, iPS cellderived RBCs have the potential to alleviate shortages and produce pathogen-free $O$ Rh-negative 'universal donor' $R B C s$. The major limitations for translating iPSC-derived RBCs into clinic are: (1) inefficient enucleation, (2) difficult switching to adult-type $(\beta)$ globin form and (3) the possibly insurmountable number of $\operatorname{RBCs}\left(10^{12}\right)$ needed to generate one unit. 
The iPS cell-derived autologous platelets have potential to alleviate supply shortages because of high demand and limited shelf-life. Production of pathogen-free $\mathrm{O}$ universal donor platelet concentrates with negligible isoagglutinin titers would be the ideal aim. The iPS cell-derived platelets have been generated ${ }^{62}$ and will be soon tested in clinical trials (Advanced Cell Technologies). The main methods are handpicking ES sacs with two-step stroma coculture or HB method with one-step stroma coculture. The major limitation is reliance on stroma and inefficiency/poor yield in megakaryocyte to platelet differentiation step.

\section{Monocytes, monocyte-derived dendritic cells (DCs) and macrophages}

Current methods for generating human primary macrophages vary in cell yield, purity and activation status, often resulting in conflicting and difficult to interpret results. The circulating monocytes are heterogeneous and vary in size, granularity, morphology and protein expression profile. Several different monocyte subsets have been characterized. ${ }^{63}$ Moreover, the method of isolation influences the properties of differentiated macrophages and monocyte-derived DCs. The primary human monocytes have a limited potential for proliferation in vitro and are difficult to transfect. Thus, development of new approaches to produce a homogenous population of macrophages is of large interest. Furthermore, the phagocytic activity of these cells limits the ability for additional genetic manipulation. Genetically modified macrophages differentiated from human iPS cells can serve as a useful model for understanding the etiology of, for example, macrophage-tropic HIV-1 disease, and facilitating the development of novel therapeutic interventions.

Because of HLA restriction of the adaptive immune response, it was soon realized that the unavailability of human ES cells genetically identical to the patients was a problem in the clinical application. Genetic modification of ES cell-derived DCs, and laborious modification of the $\beta_{2} m$ or TAP gene, has been attempted to solve the problem of HLA class I allele mismatch between human ES cells and the recipients to be treated. ${ }^{64}$ Theoretically, the histocompatibility issue may be resolved by autologous iPS cell-derived DCs. In fact, DCs derived from xenofree human iPS cells ${ }^{65}$ have been shown to be fully functional. However, animal models are needed to test the in vivo efficacy and safety of this procedure.

The monocyte-derived DCs have been widely used in cancer immunotherapy showing significant donor-to-donor variability and low capacity for the cross-presentation of tumor-associated antigens to $\mathrm{CD}^{+} \mathrm{T}$ cells. These fundamental properties reside only in $\mathrm{CD} 141^{+} \mathrm{XCR} 1^{+} \mathrm{DCs}$ that are present only in trace in peripheral blood and for this reason are not suitable for clinical application. The ability to generate a potentially unlimited source of DCs from iPS cells offers the possibility of harnessing their capacity for cross-priming cytotoxic $T$ lymphocytes inducing a tumor-specific immune response. ${ }^{66}$

Assuming allogeneic iPS cells will be used, once a clone of TAPor $\beta_{2}$ m-deficient human iPS cells is established, a premade library of clones expressing various types of HLA class I can be generated by the introduction of various HLA class I genes. Currently, TAP2deficient iPS cell clones have been generated using zinc-finger nucleases, ${ }^{67}$ and other could be achieved from patients with type I bare lymphocyte syndrome caused by mutation of the TAP1 or TAP2 gene. This will not solve the issue of HLA class II antigen matching.

\section{NK lymphocytes}

The natural lifespan for NK cells in the human body is $\sim 2$ weeks. Only few human permanent NK-like cell lines are available for research, mostly derived from NK cell leukemia or lymphoma patients, and hence lacking important features of normal NK cells.
Furthermore, several of these NK-like cell lines are latently infected with Epstein-Barr virus (EBV), and the contribution of viral effectors to cell proliferation and survival has not been studied; only recently in vitro growth transformation of functional human NK cells by Herpesvirus saimiri has been reported. ${ }^{68}$

NK lymphocytes are capable of killing cells with missing self (that is, HLA class I expression). NK cells have been generated from iPS cells and have the potential application in both cancer therapy ${ }^{69}$ and infectious diseases. ${ }^{70}$ Interleukin-2 is generally used to expand effector cytotoxic T or NK cells in vitro and in vivo, and it also promotes the expansion of $\mathrm{T}$ regulatory cells expressing the interleukin- 2 receptor $\beta$-chain CD25. As T regulatory cells are able to directly suppress both T- and NK-cell responses, the therapeutic effect of effector cells is limited. In addition, it is not completely clarified why NK cell-based immunotherapy is effective for acute myeloid leukemia but not for other hematological or solid malignancies. Genetic engineering is difficult to achieve in primary peripheral blood NK cells, whereas high-efficiency genetic modification is routinely feasible in human iPS cellderived NK cells that result in high effectiveness in animal models. Strictly considering the cell number, it seems feasible and reasonable to generate a significant amount of human iPS cellderived NK cells for adoptive immunotherapy $\left(\sim 10^{7}-10^{8}\right.$ NK cells per patient). Major limitation is reliance on two steps of stroma coculture, and the need for sorting of rare $\mathrm{CD} 34{ }^{+} \mathrm{CD} 45^{+}$cells may hinder clinical scale-up.

The fact that NK cells express all of the components to signal through the T-cell receptor (TCR) makes them particularly suitable to be used as a platform to utilize ectopic TCR expression. This approach seems to be particularly important because of lack of competition for TCR binding between endogenous and exogenous $\alpha / \beta$ subunits.

\section{T lymphocytes}

The iPS cells, by rejuvenating the original adult somatic cell, represent an interesting technology to achieve large doses of functional autologous antigen-specific $T$ lymphocytes for immunotherapy. ${ }^{71-73}$ If the TCR specificity is too rare or absent in the patient, autologous polyclonal lymphocytes can eventually be cleared of their endogenous TCR and then transfected with a chimeric antigen receptor. ${ }^{72}$ Figure 3 represents the potential approaches to achieve large doses of functional, antigen-specific autologous effector T lymphocytes, avoiding off-target toxicity. ${ }^{74}$

$T$ cells are usually derived from iPS cells through the OP9 coculture system or by the way of teratoma formation. ${ }^{41}$ The OP9 cell line ectopically expressing the Notch ligand Delta-like 1 (DI/1) or DII4 (OP9-DL1 and OP9-DL4, respectively) gains the ability to recapitulate thymus-like function, supporting T-cell differentiation of both murine and human progenitors.

\section{T lymphocytes with invariant $\alpha$-chain}

$T$ lymphocytes with invariant $\alpha$-chain act as innate $T$ lymphocytes and serving as a connection between the innate and acquired immune systems. Both type I natural killer T (NKT) cells or invariant NKT (iNKT) cells) ${ }^{75}$ and mucosa-associated invariant T cells ${ }^{76}$ have been generated from iPS cells. To date, there is no report about germline-encoded, mycolyl-reactive T cells yet.

This cell population seems to be important for the defense against mycobacteria, fungi and cancer. In fact, once iNKT cells are activated by $\alpha$-GalCer-pulsed DCs, they are capable to eliminate both $\mathrm{MHC}^{-}$and $\mathrm{MHC}^{+}$tumor cells. Both these types of tumor cells are simultaneously present in patients, and at present iNKT cells are the only known cell type capable to eliminate them. Apparently, two-thirds of patients were ineligible for this adoptive therapy because of the limited number of iNKT cells in their bodies. $^{75}$ 

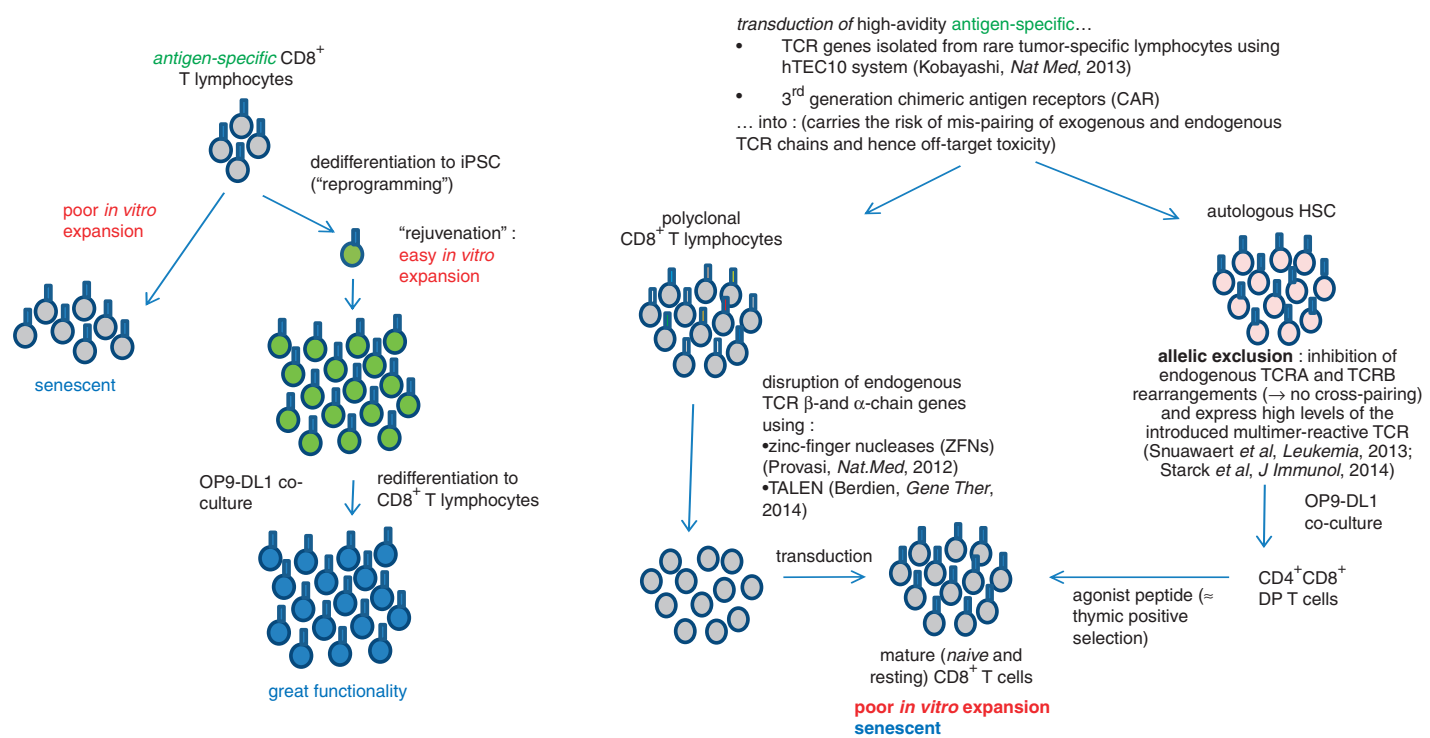

Figure 3. Current strategies to achieve large doses of antigen-specific and functional autologous effector $\mathrm{T}$ lymphocytes (see text for references).

As all these cell types are very rare, iPS cell technology for the first time will likely pave the way to adoptive cell therapies.

\section{B lymphocytes}

Despite initial issues, few reports focusing on the generation of iPS cells from B cells have been published. In parallel, it has been shown that iPS cells undergo lymphoid differentiation when cocultured with OP9 stroma cells ${ }^{77}$ or through intra-teratoma lymphopoiesis. ${ }^{41}$

Large collections of EBV-immortalized B-cell lines (EBV-B) from patients affected by various diseases have been maintained in a large number of institutions. These EBV-B cells can be an excellent resource for disease-specific iPS cell generation and banking for a variety of human diseases, especially for those patients with rare diseases whose tissues are no longer available, except as preserved EBV-transformed B cells. ${ }^{78}$

\section{Mesenchymal stem cells (MSCs)}

MSCs have been considered safe as they do not show tumor formation after transplantation and have been widely proven efficacious in preclinical and clinical studies for cardiovascular and neurodegenerative diseases, graft-versus-host disease and autoimmune disease. Systemic administrations of allogeneic MSCs (for example, Prochymal or MultiStem) do not cause any adverse effects, in part because of immunomodulatory effects. Genetically manipulated MSCs may also serve as cellular therapeutics as these cells can be used as targeted drug delivery vehicles.

MSCs from different tissues represent an interesting source for iPS cell generation. ${ }^{79}$ On the other side, MSCs have been derived from iPS cells and show preserved regenerative ${ }^{80}$ and immunomodulatory ${ }^{81}$ functions. Identification and utilization of genetically modified MSCs, having a 'safe harbor' integration, is restricted because of the limited lifespan of primary MSCs in vitro. Aging, moreover, significantly reduces the survival and differentiation potential of BM-MSCs. In contrast, using human pluripotent stem cells (human ES cells or iPS cells) can generate indefinitely fresh MSCs. Furthermore, genetically engineered MSC clones could be generated from iPS cells after an accurate screening for a vector integration sites and cells with safe harbor integrations potentially expanded nearly indefinitely. ${ }^{82}$

\section{CONCLUSIONS}

The advent of iPS cell technology produced an important milestone in hematology. The availability of patient-specific pluripotent stem cells will undoubtedly improve disease modeling, drug development and will pave the way to autologous cell therapy for many monogenic and acquired diseases. Many biotech companies are nowadays focused on iPS cells in order to generate novel effective therapeutic molecules. Currently, biotech companies are already significantly engaged and invested in the development and commercialization of iPS cells. It has been estimated that the iPS cell market is projected to grow to US\$ 1 billion by $2016 .^{83}$ Provided regulatory authorities will not pose limits to iPS cell research, ${ }^{84}$ the growing engagement of all pharmaceutical companies appear today a crucial step for translating iPS cells from bench to bedside in the coming years.

\section{CONFLICT OF INTEREST}

The authors declare no conflict of interest.

\section{ACKNOWLEDGEMENTS}

We are grateful to the Italian Society of Hematology (SIE) and the Italian League against Leukemia (AIL) for supporting funds. GA was supported by the American Italian Cancer Foundation during this work.

\section{REFERENCES}

1 Amabile G, Meissner A. Induced pluripotent stem cells: current progress and potential for regenerative medicine. Trends Mol Med 2009; 15: 59-68.

2 Takahashi K, Yamanaka S. Induction of pluripotent stem cells from mouse embryonic and adult fibroblast cultures by defined factors. Cell 2006; 126: 663-676.

3 Takahashi K, Tanabe K, Ohnuki M, Narita M, Ichisaka T, Tomoda K et al. Induction of pluripotent stem cells from adult human fibroblasts by defined factors. Cell 2007; 131: 861-872.

4 Yu J, Vodyanik MS-O K, Antosiewicz-Bourget J, Frane J, Tian S, Nie J et al. Induced pluripotent stem cell lines derived from human somatic cells. Science 2007; 318: 1917-1920.

5 Jincho Y, Araki R, Hoki Y, Tamura C, Nakamura M, Ando S et al. Generation of genome integration-free induced pluripotent stem cells from fibroblasts of C57BL/6 mice without c-Myc transduction. J Biol Chem 2010; 285: 26384-26389.

6 Li HY, Chien Y, Chen YJ, Chen SF, Chang YL, Chiang CH et al. Reprogramming induced pluripotent stem cells in the absence of c-Myc for differentiation into hepatocyte-like cells. Biomaterials 2011; 32: 5994-6005. 
7 Chiou S-H, Jiang B-H, Yu Y-L, Chou S-J, Tsai P-H, Chang W-C et al. Poly(ADP-ribose) polymerase 1 regulates nuclear reprogramming and promotes IPSC generation without c-Myc. J Exp Med 2013; 210: 85-98.

8 Doege CA, Inoue K, Yamashita T, Rhee DB, Travis S, Fujita R et al. Early-stage epigenetic modification during somatic cell reprogramming by Parp1 and Tet2. Nature 2012; 488: 652-655.

9 Griscelli F, Feraud O, Oudrhiri N, Gobbo E, Casal I, Chomel JC et al. Malignant germ cell-like tumors, expressing Ki-1 antigen (CD30), are revealed during in vivo differentiation of partially reprogrammed human-induced pluripotent stem cells. Am J Pathol 2012; 180: 2084-2096.

10 Sommer CA, Christodoulou C, Gianotti-Sommer A, Shen SS, Sailaja BS, Hezroni H et al. Residual expression of reprogramming factors affects the transcriptional program and epigenetic signatures of induced pluripotent stem cells. PLOS One 2012; 7: e51711.

11 Sommer CA, Mostoslavsky G. Experimental approaches for the generation of induced pluripotent stem cells. Stem Cell Res Ther 2010; 1: 26.

12 Dekelver RC, Choi VM, Moehle EA, Paschon DE, Hockemeyer D, Meijsing SH et al. Functional genomics, proteomics, and regulatory DNA analysis in isogenic settings using zinc finger nuclease-driven transgenesis into a safe harbor locus in the human genome. Genome Res 2010; 20: 1133-1142.

13 Bayart E, Cohen-Haguenauer O. Technological overview of iPS induction from human adult somatic cells. Curr Gene Ther 2013; 13: 73-92.

14 Zimmermann A, Preynat-Seauve O, Tiercy JM, Krause KH, Villard J. Haplotypebased banking of human pluripotent stem cells for transplantation: potential and limitations. Stem Cells Dev 2012; 21: 2364-2373.

15 Kim EM, Manzar G, Zavazava N. Human iPS cell-derived hematopoietic progenitor cells induce T-cell anergy in in vitro-generated alloreactive CD8(+) T cells. Blood 2013; 121: 5167-5175.

16 Liu Z, Wen X, Wang H, Zhou J, Zhao M, Lin Q et al. Molecular imaging of induced pluripotent stem cell immunogenicity with in vivo development in ischemic myocardium. PLoS One 2013; 8: e66369.

17 Zhao T, Zhang Z-N, Rong Z, Xu Y. Immunogenicity of induced pluripotent stem cells. Nature 2011; 474: 212-215.

18 Araki $R$, Uda $M$, Hoki $Y$, Sunayama $M$, Nakamura $M$, Ando $S$ et al. Negligible immunogenicity of terminally differentiated cells derived from induced pluripotent or embryonic stem cells. Nature 2013; 494: 100-104.

19 Dhodapkar KM, Feldman D, Matthews P, Radfar S, Pickering R, Turkula S et al. Natural immunity to pluripotency antigen OCT4 in humans. Proc Natl Acad Sci USA 2010; 107: 8718-8723.

20 Garcon L, Ge J, Manjunath SH, Mills JA, Apicella M, Parikh S et al. Ribosomal and hematopoietic defects in induced pluripotent stem cells derived from Diamond Blackfan anemia patients. Blood 2013; 122: 912-921.

21 Raya A, Rodriguez-Piza I, Guenechea G, Vassena R, Navarro S, Barrero MJ et al. Disease-corrected haematopoietic progenitors from Fanconi anaemia induced pluripotent stem cells. Nature 2009; 460: 53-59.

22 Kinoshita T, Nagamatsu G, Kosaka T, Takubo K, Hotta A, Ellis J et al. Ataxia-telangiectasia mutated (ATM) deficiency decreases reprogramming efficiency and leads to genomic instability in iPS cells. Biochem Biophys Res Commun 2011; 407: 321-326.

23 Raya A, Rodriguez-Piza I, Navarro S, Richaud-Patin Y, Guenechea G, Sanchez-Danes A et al. A protocol describing the genetic correction of somatic human cells and subsequent generation of iPS cells. Nat Protoc 2010; 5: 647-660.

24 Dong A, Rivella S, Breda L. Gene therapy for hemoglobinopathies: progress and challenges. Transl Res 2013; 161: 293-306.

25 Tubsuwan A, Abed S, Deichmann A, Kardel MD, Bartholoma C, Cheung A et al. Parallel assessment of globin lentiviral transfer in induced pluripotent stem cells and adult hematopoietic stem cells derived from the same transplanted betathalassemia patient. Stem Cells 2013; 31: 1785-1794.

26 Cavazzana-Calvo M, Payen E, Negre O, Wang G, Hehir K, Fusil F et al. Transfusion independence and HMGA2 activation after gene therapy of human beta-thalassaemia. Nature 2010; 467: 318-322.

27 Ma N, Liao B, Zhang H, Wang L, Shan Y, Xue Y et al. TALEN-mediated gene correction in integration-free beta-thalassemia iPSCs. J Biol Chem 2013; 288: 34671-34679.

28 Chang CJ, Bouhassira EE. Zinc-finger nuclease-mediated correction of alpha-thalassemia in iPS cells. Blood 2012; 120: 3906-3914.

29 Romero Z, Urbinati F, Geiger S, Cooper AR, Wherley J, Kaufman ML et al. beta-globin gene transfer to human bone marrow for sickle cell disease. J Clin Invest 2013; 1: Pii: 67930.

30 Wu L-C, Sun C-W, Ryan TM, Pawlik KM, Ren J, Townes TM. Correction of sickle cell disease by homologous recombination in embryonic stem cells. Blood 2006; 108: 1183-1188.

31 Hanna J, Wernig M, Markoulaki S, Sun CW, Meissner A, Cassady JP et al. Treatment of sickle cell anemia mouse model with iPS cells generated from autologous skin. Science 2007; 318: 1920-1923.
32 Zou J, Mali P, Huang X, Dowey SN, Cheng L. Site-specific gene correction of a point mutation in human iPS cells derived from an adult patient with sickle cell disease. Blood 2011; 118: 4599-4608.

33 Giorgetti A, Montserrat N, Rodriguez-Piza I, Azqueta C, Veiga A, lzpisua Belmonte JC. Generation of induced pluripotent stem cells from human cord blood cells with only two factors: Oct4 and Sox2. Nat Protoc 2010; 5: 811-820.

34 Ohmine S, Dietz AB, Deeds MC, Hartjes KA, Miller DR, Thatava T et al. Induced pluripotent stem cells from GMP-grade hematopoietic progenitor cells and mononuclear myeloid cells. Stem Cell Res Ther 2011; 2: 46.

35 Merling RK, Sweeney CL, Choi U, De Ravin SS, Myers TG, Otaizo-Carrasquero F et al. Transgene-free iPSCs generated from small volume peripheral blood nonmobilized CD34 + cells. Blood 2013; 121: e98-107.

36 Gori JL, Chandrasekaran D, Kowalski JP, Adair JE, Beard BC, D'Souza SL et al. Efficient generation, purification, and expansion of CD34(+) hematopoietic progenitor cells from nonhuman primate-induced pluripotent stem cells. Blood 2012; 120: e35-e44.

37 Slukvin II. Hematopoietic specification from human pluripotent stem cells: current advances and challenges toward de novo generation of hematopoietic stem cells. Blood 2013; 122: 4035-4046.

38 Gao J, Yan XL, Li R, Liu Y, He W, Sun S et al. Characterization of OP9 as authentic mesenchymal stem cell line. J Genet Genomics 2010; 37: 475-482.

39 Woods NB, Parker AS, Moraghebi R, Lutz MK, Firth AL, Brennand KJ et al. Brief report: efficient generation of hematopoietic precursors and progenitors from human pluripotent stem cell lines. Stem Cells 2011; 29: 1158-1164.

40 Kitajima K, Minehata K, Sakimura K, Nakano T, Hara T. In vitro generation of HSC-like cells from murine ESCs/iPSCs by enforced expression of LIM-homeobox transcription factor Lhx2. Blood 2011; 117: 3748-3758.

41 Amabile G, Welner RS, Nombela-Arrieta C, D'Alise AM, Di Ruscio A, Ebralidze AK et al. In vivo generation of transplantable human hematopoietic cells from induced pluripotent stem cells. Blood 2013; 121: 1255-1264.

42 Suzuki N, Yamazaki S, Yamaguchi T, Okabe M, Masaki H, Takaki S et al. Generation of engraftable hematopoietic stem cells from induced pluripotent stem cells by way of teratoma formation. Mol Ther 2013; 21: 1424-1431.

43 Wang L, Li L, Shojaei F, Levac K, Cerdan C, Menendez P et al. Endothelial and hematopoietic cell fate of human embryonic stem cells originates from primitive endothelium with hemangioblastic properties. Immunity 2004; 21: 31-41.

44 Wang L, Menendez P, Shojaei F, Li L, Mazurier F, Dick JE et al. Generation of hematopoietic repopulating cells from human embryonic stem cells independent of ectopic HOXB4 expression. J Exp Med 2005; 201: 1603-1614.

$45 \mathrm{Ng}$ ES, Davis RP, Azzola L, Stanley EG, Elefanty AG. Forced aggregation of defined numbers of human embryonic stem cells into embryoid bodies fosters robust, reproducible hematopoietic differentiation. Blood 2005; 106: 1601-1603.

46 Pick M, Azzola L, Mossman A, Stanley EG, Elefanty AG. Differentiation of human embryonic stem cells in serum-free medium reveals distinct roles for bone morphogenetic protein 4, vascular endothelial growth factor, stem cell factor, and fibroblast growth factor 2 in hematopoiesis. Stem Cells 2007; 25: 2206-2214.

47 Ledran MH, Krassowska A, Armstrong L, Dimmick I, Renstrom J, Lang R et al. Efficient hematopoietic differentiation of human embryonic stem cells on stromal cells derived from hematopoietic niches. Cell Stem Cell 2008; 3: 85-98.

48 Wang $Y$, Yates F, Naveiras O, Ernst P, Daley GQ. Embryonic stem cell-derived hematopoietic stem cells. Proc Natl Acad Sci USA 2005; 102: 19081-19086.

49 Lu M, Kardel MD, O'Connor MD, Eaves CJ. Enhanced generation of hematopoietic cells from human hepatocarcinoma cell-stimulated human embryonic and induced pluripotent stem cells. Exp Hematol 2009; 37: 924-936.

50 Wang N, Rajasekaran N, Hou T, Lisowski L, Mellins ED. Comparison of transduction efficiency among various lentiviruses containing GFP reporter in bone marrow hematopoietic stem cell transplantation. Exp Hematol 2013; 41: 934-943.

51 Joung JK, Sander JD. TALENs: a widely applicable technology for targeted genome editing. Nat Rev Mol Cell Biol 2013; 14: 49-55.

52 Eggenschwiler R, Loya K, Wu G, Sharma AD, Sgodda M, Zychlinski $D$ et al. Sustained knockdown of a disease-causing gene in patient-specific induced pluripotent stem cells using lentiviral vector-based gene therapy. Stem Cells Transl Med 2013; 2: 641-654.

53 Sung YH, Kim JM, Kim HT, Lee J, Jeon J, Jin Y et al. Highly efficient gene knockout in mice and zebrafish with RNA-guided endonucleases. Genome Res 2013; 24: 125-131.

54 Zou J, Sweeney CL, Chou BK, Choi U, Pan J, Wang H et al. Oxidase-deficient neutrophils from $\mathrm{X}$-linked chronic granulomatous disease iPS cells: functional correction by zinc finger nuclease-mediated safe harbor targeting. Blood 2011; 117: 5561-5572.

55 Sebastiano V, Maeder ML, Angstman JF, Haddad B, Khayter C, Yeo DT et al. In situ genetic correction of the sickle cell anemia mutation in human induced pluripotent stem cells using engineered zinc finger nucleases. Stem Cells 2011; 29: 1717-1726. 
56 Sakuma T, Hosoi S, Woltjen K, Suzuki K, Kashiwagi K, Wada H et al. Efficient TALEN construction and evaluation methods for human cell and animal applications. Genes Cells 2013; 18: 315-326.

57 Horii T, Tamura D, Morita S, Kimura M, Hatada I. Generation of an ICF syndrome model by efficient genome editing of human induced pluripotent stem cells using the CRISPR system. Int J Mol Sci 2013; 14: 19774-19781.

58 Hou Z, Zhang Y, Propson NE, Howden SE, Chu LF, Sontheimer EJ et al. Efficient genome engineering in human pluripotent stem cells using Cas9 from Neisseria meningitidis. Proc Natl Acad Sci USA 2013; 110: 15644-15649.

59 Mali P, Yang L, Esvelt KM, Aach J, Guell M, DiCarlo JE et al. RNA-guided human genome engineering via Cas9. Science 2013; 339: 823-826.

60 Li M, Suzuki K, Kim NY, Liu GH, Izpisua Belmonte JC. A cut above the rest: targeted genome editing technologies in human pluripotent stem cells. J Biol Chem 2013, 289: 4594-4599.

61 Shah S, Huang X, Cheng L. Concise review: stem cell-based approaches to red blood cell production for transfusion. Stem Cells Transl Med 2013; 3: 346-355.

62 Nakagawa Y, Nakamura S, Nakajima M, Endo H, Dohda T, Takayama N et al. Two differential flows in a bioreactor promoted platelet generation from human pluripotent stem cell-derived megakaryocytes. Exp Hematol 2013; 41: 742-748.

63 Wong KL, Yeap WH, Tai JJ, Ong SM, Dang TM, Wong SC. The three human monocyte subsets: implications for health and disease. Immunol Res 2012; 53: 41-57.

64 Matsunaga Y, Fukuma D, Hirata S, Fukushima S, Haruta M, lkeda T et al. Activation of antigen-specific cytotoxic T lymphocytes by beta 2-microglobulin or TAP1 gene disruption and the introduction of recipient-matched MHC class I gene in allogeneic embryonic stem cell-derived dendritic cells. J Immunol 2008; 181 6635-6643.

65 Yanagimachi MD, Niwa A, Tanaka T, Honda-Ozaki F, Nishimoto S, Murata Y et al. Robust and highly-efficient differentiation of functional monocytic cells from human pluripotent stem cells under serum- and feeder cell-free conditions. PLoS One 2013; 8: e59243.

66 Silk KM, Silk JD, Ichiryu N, Davies TJ, Nolan KF, Leishman AJ et al. Cross-presentation of tumour antigens by human induced pluripotent stem cell-derived CD141(+)XCR1 + dendritic cells. Gene Ther 2012; 19: 1035-1040.

67 Haruta M, Tomita Y, Yuno A, Matsumura K, Ikeda T, Takamatsu K et al. TAP-deficient human iPS cell-derived myeloid cell lines as unlimited cell source for dendritic cell-like antigen-presenting cells. Gene Ther 2013; 20: 504-513.

68 Vogel B, Tennert K, Full F, Ensser A. Efficient generation of human natural killer cell lines by viral transformation. Leukemia 2014; 28: 192-195.

69 Knorr DA, Ni Z, Hermanson D, Hexum MK, Bendzick L, Cooper LJ et al. Clinical-scale derivation of natural killer cells from human pluripotent stem cells for cancer therapy. Stem Cells Transl Med 2013; 20: 274-283.

$70 \mathrm{Ni}$ Z, Knorr DA, Clouser CL, Hexum MK, Southern P, Mansky LM et al. Human pluripotent stem cells produce natural killer cells that mediate anti-HIV-1 activity by utilizing diverse cellular mechanisms. J Virol 2011; 85: 43-50.

71 Vizcardo R, Masuda KY, D, Ikawa TS, Fujii SK K, HKawamoto H. Regeneration of human tumor antigen-specific $T$ cells from iPSCs derived from mature CD8 $(+)$ T cells. Cell Stem Cell 2013; 12: 31-36.
72 Themeli M, Kloss CC, Ciriello G, Fedorov VD, Perna F, Gonen M et al. Generation of tumor-targeted human $T$ lymphocytes from induced pluripotent stem cells for cancer therapy. Nat Biotechnol 2013; 31: 928-933.

73 Nishimura T, Kaneko S, Kawana-Tachikawa A, Tajima Y, Goto H, Zhu DN-H et al. Generation of rejuvenated antigen-specific $T$ cells by reprogramming to pluripotency and redifferentiation. Cell Stem Cell 2013; 12: 114-126.

74 Linette GP, Stadtmauer EA, Maus MV, Rapoport AP, Levine BL, Emery L et al. Cardiovascular toxicity and titin cross-reactivity of affinity-enhanced $T$ cells in myeloma and melanoma. Blood 2013; 122: 863-871.

75 Watarai H, Yamada D, Fujii S, Taniguchi M, Koseki H. Induced pluripotency as a potential path towards iNKT cell-mediated cancer immunotherapy. Int J Hematol 2012; 95: 624-631.

76 Wakao H, Yoshikiyo K, Koshimizu U, Furukawa T, Enomoto K, Matsunaga T et al. Expansion of functional human mucosal-associated invariant $\mathrm{T}$ cells via reprogramming to pluripotency and redifferentiation. Cell Stem Cell 2013; 12: 546-558.

77 Carpenter L, Malladi R, Yang CT, French A, Pilkington KJ, Forsey RW et al. Human induced pluripotent stem cells are capable of B-cell lymphopoiesis. Blood 2011; 117: 4008-4011.

78 Rajesh D, Dickerson SJ, Yu J, Brown ME, Thomson JA, Seay NJ. Human lymphoblastoid B-cell lines reprogrammed to EBV-free induced pluripotent stem cells. Blood 2011; 118: 1797-1800.

79 Ge X, Wang IN, Toma I, Sebastiano V, Liu J, Butte MJ et al. Human amniotic mesenchymal stem cell-derived induced pluripotent stem cells may generate a universal source of cardiac cells. Stem Cells Dev 2012; 21: 2798-2808.

80 Moslem M, Valojerdi MR, Pournasr B, Muhammadnejad A, Baharvand H. Therapeutic potential of human induced pluripotent stem cell-derived mesenchymal stem cells in mice with lethal fulminant hepatic failure. Cell Transplant 2013; 22: 1785-1799.

81 Sun YQ, Deng MX, He J, Zeng QX, Wen W, Wong DS et al. Human pluripotent stem cell-derived mesenchymal stem cells prevent allergic airway inflammation in mice. Stem Cells 2012; 30: 2692-2699.

82 Jung Y, Bauer G, Nolta JA. Concise review: Induced pluripotent stem cell-derived mesenchymal stem cells: progress toward safe clinical products. Stem Cells 2012 30: 42-47.

83 Razvi E. iPSC quantitative market opportunity. GENReports: Market \& Tech Analysis 2014. Available from http://www.genengnews.com/media/pdf/GEN Biomarket_Trends_Report_iPSC_Market_Opportunity.pdf.

84 Nielen MG, de Vries SA, Geijsen N. European stem cell research in legal shackles. $E M B O$ J 2013; 32: 3107-3111.

(1) This work is licensed under a Creative Commons AttributionBY NC SA NonCommercial-ShareAlike 3.0 Unported License. The images or other third party material in this article are included in the article's Creative Commons license, unless indicated otherwise in the credit line; if the material is not included under the Creative Commons license, users will need to obtain permission from the license holder to reproduce the material. To view a copy of this license, visit http:// creativecommons.org/licenses/by-nc-sa/3.0/ 